\title{
Ueber den Zucker im normalen Hühnerblute.
}

\author{
Von
}

S. Saito und K. Katsuyama.

(Aus dem medicinisch-chemischen Institut der Kaiserl. Universität Kyoto.)

(Der Redaction zugegangen am 23. Januar 1901.)

Durch die Untersuchungen von Seegen, Miura und Pickardt ist es bereits zweifellos gemacht, dass der im Blute des Hundes und Rindes vorhandene Zucker mit d-Glucose identisch ist. Dagegen liegen über die Natur des Zuckers im normalen Vogelblute bisher nur spärliche Angaben vor.

Gelegentlich der Untersuchung über den Pankreasdiabetes der Vögel hat Weintraud ${ }^{1}$ ) eine grosse Anzahl von Zuckerbestimmungen im normalen Entenblute ausgeführt. Er gibt an, in 11 Versuchen $0,132-0,198 \%$ Zucker gefunden zu haben. Da er aber nichts Weiteres in seiner Abhandlung angab, als: "Die Bestimmungen wurden nach der Abel'schen Methode nach Beseitigung des Eiweisses mittelst alkoholischer Zinkacetatlösung gemacht, meist an $30-40 \mathrm{~g}$ Blut, das in den späteren Versuchen immer erst nach vorausgegangenem 24 stündigen Hungern den Thieren entnommen wurde", so ist es nicht möglich, ein Urtheil darüber zu gewinnen, ob er wirklich $d$-Glucose analysirt hat.

$\mathrm{Kausch}^{2}$ ) versuchte den Zuckergehalt des Blutes normaler Enten und Gänse festzustellen und sah, dass derselbe bei verschiedener Diät zwischen $0,12-0,18 \%$ schwankt. Ueber die Natur seines Zuckers hat Kausch Folgendes angegeben: «Mit dem enteiweissten Blut normaler Vögel wurde öfters die "Osazonprobe angestellt, die stets einen ziemlichen Nieder«schlag von Krystallen ergab, welche unter dem Mikroskop

1) Weintraud, Archiv f. exper. Pathol. u. Pharmacol., Bd. XXXIV, S. 309 .

2) Archiv f. exper. Pathol. u. Pharmacol., Bd. XXXVII, S. 283. 
"das Aussehen von Glycosazon hatten. Schmelzpunkt*bestimmungen wurden bisher Mangels genügender "Menge noch nicht ausgeführt. Im Saccharimeter wurde «bald Drehung 0, bald Spur Rechtsdrehung gefunden, "doch fiel letztere noch in die Fehlergrenzen des "benutzten Apparates. Auch die Gährfähigkeit durch «Saccharomyces apiculatus wurde mehrfach nachgewiesen."

Diese Beobachtungen sprechen nur für die Gegenwart von einem gährfähigen Zucker im normalen Vogelblute; welcher Art dieser Zucker sein soll, darüber ist leider keine völlige Klarheit vorhanden. Um diese Lücke auszufüllen, haben wir die nachstehenden Versuche angestellt.

Das Blut wurde stets aus den Halsgefässen von den mit Reis gefütterten Hühnern entnommen und durch das Verfahren von Abeles ${ }^{1}$ ) enteiweisst. Wir haben den Zucker im eiweissfreien Filtrat erstens durch Reduction einer auf Traubenzucker titrirten Fehling'schen Kupferlösung und zweitens mittelst eines für die Bestimmung von Traubenzucker construirten Polarisationsapparates von Soleil-Ventzke bestimmt. Wir haben ferner Osazon dargestellt und dessen Schmelzpunkt bestimmt. Um uns volle Gewissheit zu verschaffen, haben wir endlich die Gährfähigkeit durch Bierhefe untersucht.

\section{Versuch.}

In $155 \mathrm{~g}$ Blut wurden gefunden:

Mit dem Polarisationsapparate . . . . . . 0,250\% Zucker. Durch die Reduction der Fehling'schen Lösung . . 0,250, ,

Das in bekannter Weise dargestellte Osazon krystallisirte in gelben Nadeln und schmolz bei $204^{\circ} \mathrm{C}$.

\section{Versuch.}

In $102 \mathrm{~g}$ Blut wurden gefunden:

Mit dem Polarisationsapparate . . . . . . . . 0,200 \% Zucker. Durch die Reduction der Fehling'schen Lösung . . 0,208 ” ,

Das Osazon besass alle Charaktere des Glucosazons und schmolz bei $204^{\circ} \mathrm{C}$.

1) A beles, Zeitschrift f. physiolog. Chemie, Bd. XV, S. 435 . 


\section{Versuch.}

In $28 \mathrm{~g}$ Blut wurden gefunden: Mit dem Polarisationsapparate . . . . . . . 0 0,200\% Zucker. Durch die Reduction der Fehling'schen Lösung . . 0,220 , ,

Die Portion, welche zur Untersuchung mit dem Saccharimeter verwendet wurde, wurde hier ebenso, wie bei den Versuchen $4-8$ gleich zur Titrirung benutzt.

\section{Versuch.}

In $28 \mathrm{~g}$ Blut wurden gefunden: Mit dem Polarisationsapparate . . . . . . 0 0,200\% Zucker. Durch die Reduction der Fehling'schen Lösung . . 0,208 , ,

\section{Versuch.}

In $29 \mathrm{~g}$ Blut wurden gefunden: Mit dem Polarisationsapparate . . . . . . . 0,200\% Zucker. Durch die Reduction der Fehling'schen Lösung . . 0,192 , ,

\section{Versuch.}

In $25 \mathrm{~g}$ Blut wurden gefunden: Mit dem Polarisationsapparate . . . . . . . 0 0,200\% Zucker. Durch die Reduction der Fehling'schen Lösung . . 0,188 , ,

7. Versuch.

In $35 \mathrm{~g}$ Blut wurden gefunden: Mit dem Polarisationsapparate . . . . . . . 0,200\% Zucker. Durch die Reduction der Fehling'schen Lösung . . 0,200, ,

8. Versuch.

In $33 \mathrm{~g}$ Blut wurden gefunden: Mit dem Polarisationsapparate . . . . . . . 0,200\% Zucker. Durch die Reduction der Fehling'schen Lösung . . 0,208 , ,

9. Versuch.

$193 \mathrm{~g}$ Blut wurden nach der Enteiweissung auf kleines Volumen verdunstet, mit Essigsäure schwach angesäuert und dann zur Gährungsprobe verwendet.

Das bei der Gährung entwickelte Gas wurde durch eine Kalikugel vollständig absorbirt. Die vergohrene Flüssigkeit wurde in einem Kolben der Destillation unterworfen; das Destillat gab Jodoformreaction und mit $\mathrm{H}_{2} \mathrm{SO}_{4}+\mathrm{K}_{2} \mathrm{CrO}_{4}$ Aldehydreaction. 
Somit ist mit Sicherheit erwiesen, dass der Zucker durch Bierhefe in Kohlensäure und Alkohol zerlegt wurde.

Die gewonnenen Resultate stellen wir übersichtlich in folgender Tabelle zusammen:

Tabelle.

\begin{tabular}{|c|c|c|c|c|}
\hline \multirow{2}{*}{$\begin{array}{l}\text { Ver- } \\
\text { suchs- } \\
\text { Nr. }\end{array}$} & \multirow{2}{*}{$\begin{array}{c}\text { Die Quantität } \\
\text { des } \\
\text { verwendeten } \\
\text { Blutes } \\
\text { in } \mathbf{g}\end{array}$} & \multicolumn{2}{|c|}{$\begin{array}{l}\text { Die gefundenen Mengen des } \\
\text { Zuckers in Procent. }\end{array}$} & \multirow{2}{*}{ Bemerkungen. } \\
\hline & & $\begin{array}{l}\text { Mit dem } \\
\text { Polarisations- } \\
\text { apparate }\end{array}$ & $\begin{array}{l}\text { Durch die } \\
\text { Titrirung }\end{array}$ & \\
\hline 1 & 155 & 0,250 & 0,250 & $\begin{array}{l}\text { Das Osazon schmilzt bei } \\
204^{\circ} \mathrm{C} .\end{array}$ \\
\hline 2 & 102 & 0,200 & 0,208 & $\begin{array}{l}\text { Das Osazon schmilzt bei } \\
204^{\circ} \mathrm{C} \text {. }\end{array}$ \\
\hline 3 & 28 & 0,200 & 0,220 & \\
\hline 4 & 28 & 0,200 & 0,208 & \\
\hline 5 & 29 & 0,200 & 0,192 & . \\
\hline 6 & 25 & 0,200 & 0,188 & \\
\hline 7 & 35 & 0,200 & 0,200 & \\
\hline 8 & 33 & 0,200 & 0,208 & \\
\hline 9 & 一 & 一 & - & $\begin{array}{l}\text { Durch Gährung wird der } \\
\text { Zucker in } \mathrm{CO}_{2} \text { und Alko- } \\
\text { hol zerlegt. }\end{array}$ \\
\hline
\end{tabular}

Wie aus der Tabelle ersichtlich ist, decken sich die Mengen des durch die Titrirung, wie des durch die polarimetrische Bestimmung gefundenen Zuckers nahezu vollständig; die Phenylhydrazin- und Gährungsprobe zeigen auch übereinstimmend, dass der Zucker mit d-Glucose identisch ist. Es lässt sich nicht mehr verkennen, dass das normale Hühnerblut d-Glucose als einen constanten Bestandtheil enthält. Die in die Tabelle eingetragenen Ziffern machen ferner zweifellos, dass bei Hühnern der Gehalt des Blutes an Zucker viel höher ist, als bei Hunden und Kaninchen.

Kyoto, den 14. December 1900. 